\title{
The Effects of Transdermal Nicotine on Cognition in Nonsmokers with Schizophrenia and Nonpsychiatric Controls
}

\author{
Ruth S Barr ${ }^{1,2,3}$, Melissa A Culhane ${ }^{1,2}$, Lindsay E Jubelt', Rana S Mufti ${ }^{1,2,3}$, Michael A Dyer ${ }^{1,2}$, \\ Anthony P Weiss ${ }^{1,3}$, Thilo Deckersbach ${ }^{3,4}$, John F Kelly ${ }^{2,3}$, Oliver Freudenreich ${ }^{1,3}$, Donald C Goff ${ }^{1,3}$ \\ and A Eden Evins*, 1,2,3
}

'The Schizophrenia Program of the Massachusetts General Hospital, Boston, MA, USA; ${ }^{2}$ The Addiction Research Program of the Massachusetts General Hospital, Boston, MA, USA; ${ }^{3}$ Harvard Medical School, Boston, MA, USA; ${ }^{4}$ Cognitive Neuroscience Program of the Massachusetts General Hospital, Boston, MA, USA

\begin{abstract}
Abundant evidence indicates that the neuronal nicotinic acetylcholine receptor ( $\mathrm{nAChR}$ ) system is integral to regulation of attentional processes and is dysregulated in schizophrenia. Nicotinic agonists may have potential for the treatment of cognitive impairment in this disease. This study investigated the effects of transdermal nicotine on attention in individuals with schizophrenia $(n=28)$ and healthy controls $(n=32)$. All participants were nonsmokers in order to eliminate confounding effects of nicotine withdrawal and reinstatement that may occur in the study of smokers. Subjects received $14 \mathrm{mg}$ transdermal nicotine and identical placebo in a randomized, placebocontrolled, crossover design. A cognitive battery was conducted before and $3 \mathrm{~h}$ after each patch application. The primary outcome measure was performance on the Continuous Performance Test Identical Pairs (CPT-IP) Version. Nicotine significantly improved the performance on the CPT-IP as measured by hit reaction time, hit reaction time standard deviation and random errors in both groups. In addition, nicotine reduced commission errors on the CPT-IP and improved the performance on a Card Stroop task to a greater extent in those with schizophrenia vs controls. In summary, nicotine improved attentional performance in both groups and was associated with greater improvements in inhibition of impulsive responses in subjects with schizophrenia. These results confirm previous findings that a single dose of nicotine improves attention and suggest that nicotine may specifically improve response inhibition in nonsmokers with schizophrenia.

Neuropsychopharmacology (2008) 33, 480-490; doi: I0.1038/sj.npp. I 30 I423; published online I8 April 2007
\end{abstract}

Keywords: schizophrenia; nicotine; smoking; cognition; attention; nonsmokers

\section{INTRODUCTION}

Accumulated evidence suggests that dysregulation of the neuronal nicotinic acetylcholine receptor (nAChR) system contributes to the pathophysiology of schizophrenia. Postmortem studies have revealed a reduction in lowaffinity nAChRs in the hippocampus, and reduced smokingrelated upregulation of high-affinity nAChRs in the cortex, hippocampus, and caudate at all levels of smoking compared with controls (Freedman et al, 1995; Breese et al, 2000). Deficient P50 auditory sensory gating has been linked to polymorphisms at the site of the $\alpha 7 \mathrm{nAChR}$ gene on chromosome 15q14 and is transiently reversed by nicotine

These data have been accepted for presentation in part at the International Congress on Schizophrenia Research, Colorado Springs, 30 March 2007.

*Correspondence: Dr AE Evins, Schizophrenia Program and Director, Addiction Research Program Massachusetts General Hospital, 25 Staniford Street, Boston, MA 02 I |4, USA, Tel: + | 617912 7832, Fax: + | 617723 3919, E-mail: a_eden_evins@hms.harvard.edu

Received 26 January 2007; revised 12 March 2007; accepted 13 March 2007 administration in smokers with schizophrenia and in nonsmoking first-degree relatives of patients with schizophrenia (Adler et al, 1992, 1993; Freedman et al, 1997; Leonard et al, 2002). Nicotine also improves diseaseassociated deficits in prepulse inhibition (PPI) of the acoustic startle response (Kumari et al, 2001) and oculomotor function, with improvements reported in smooth pursuit eye movement (SPEM) and antisaccade error rates (Olincy et al, 1998, 2003; Depatie et al, 2002; Sherr et al, 2002; Avila et al, 2003). These findings, combined with the observation that the prevalence of cigarette smoking is much higher in schizophrenia compared with the general population, (Hughes, 1986; de Leon et al, 2002) have led to the hypothesis that smoking represents a form of self-medication for patients with psychiatric illness, particularly schizophrenia (Glassman, 1993; Dalack et al, 1998; Kumari and Postma, 2005).

Cognitive dysfunction is thought to have a significant impact on functional outcome in schizophrenia, and intensive research is being focused on identification of treatments for cognitive impairment in this disorder (Green, 1996, 2000; Marder and Fenton, 2004; Marder 
et al, 2004). There is increasing evidence that $\mathrm{nAChR}$ stimulation has beneficial effects on cognitive function in schizophrenia, possibly via presynaptic modulation of dopamine and/or glutamate release (McGehee et al, 1995; George et al, 2000; Picciotto et al, 2000; Wonnacott et al, 2000). The administration of both short- and long-acting preparations of nicotine to individuals with schizophrenia has been associated with improved neuropsychological performance (Levin et al, 1996b; Depatie et al, 2002; Smith et al, 2002, 2006; Harris et al, 2004; Jacobsen et al, 2004; Myers et al, 2004). Acute administration of the selective $\alpha 7 \mathrm{nAChR}$ partial agonist, DMXB-A, improved P50 gating compared with placebo (Olincy et al, 2006) and administration of the nAChR antagonist, mecamylamine, blocked smoking-associated improvements in performance on attentional and visuospatial working memory (VSWM), implying that $\mathrm{nAChR}$ activation mediates smoking-related cognitive enhancement (Sacco et al, 2005). If $\mathrm{nAChR}$ activation improves cognitive dysfunction in schizophrenia, then smoking abstinence would be expected to result in deterioration in cognitive performance. Performance on a VSWM task deteriorated in those with schizophrenia and improved in smokers with no psychiatric illness during early smoking abstinence (George et al, 2002), and seven days of smoking abstinence resulted in significant impairments in psychomotor performance amongst smokers with schizophrenia (Evins et al, 2005b).

In summary, current evidence suggests that nicotinic agonists may have a therapeutic use for the treatment of cognitive dysfunction in schizophrenia and possibly other neuropsychiatric disorders (Levin et al, 1996a; White and Levin, 1999; Kelton et al, 2000). However, many studies investigating the effects of nicotinic stimulation in schizophrenia have been conducted in smokers who have undergone a brief period of abstinence from smoking prior to testing of nicotine effects. Under such circumstances, cognitive benefits observed following the nicotine administration may be confounded by reversal of nicotine withdrawal symptoms or limited by tachyphylaxis (Harris et al, 2004). We, therefore, performed the following study to investigate the acute effects of nicotine on cognition in nonsmokers with schizophrenia and healthy controls. We selected a measure of attention as our primary outcome as the nAChR system is thought to play an integral role in the regulation of attentional processes (Mansvelder et al, 2006) and several previous studies have reported an improvement in this cognitive domain following nicotine administration in individuals with schizophrenia (Depatie et al, 2002; Harris et al, 2004; Sacco et al, 2005; Smith et al, 2006). Our primary hypothesis was that nicotine would enhance attention in nonsmokers with schizophrenia and controls; and the secondary hypothesis was that nicotine-associated improvements in cognition would be greater in the schizophrenia group compared with controls.

\section{METHODS}

\section{Participants}

We conducted a randomized, double-blind, placebo-controlled, crossover study of the effects of nicotine on cognition in nonsmokers with schizophrenia and healthy controls. The study was carried out in accordance with the Declaration of Helsinki and was approved by the Institutional Review Boards of the Massachusetts Department of Mental Health and the Massachusetts General Hospital. All participants were assessed by a doctoral level investigator as competent to consent and signed informed consent prior to participation.

Nonsmokers with schizophrenia on a stable dose of antipsychotic medication were recruited from the outpatient population of an urban community mental health clinic. Diagnosis of schizophrenia or schizoaffective disorder depressed type by DSM-IV criteria was confirmed by clinical interview and medical record review by a study psychiatrist (RB or EE). Control participants were recruited using advertising in local press and internet sites. Eligible participants were aged 18-65 years, scored $\geqslant 35$ on the Wide Range Achievement Test-3rd version (WRAT 3 blue form, Jastak Associates, Wilmington, DE, USA), and were nonsmokers for $\geqslant 3$ months prior to enrollment. Self-report of nonsmoking status was confirmed by semi-quantitative salivary cotinine $<10 \mathrm{ng} / \mathrm{ml}$ (Nicalert ${ }^{\mathrm{TM}}$, JANT Pharmacal Corporation, Encino, CA, USA) and expired air carbon monoxide (CO) <9 p.p.m., measured using a Bedfont Micro Smokerlyzer III (Bedfont Scientific Ltd., Kent, UK). Subjects were excluded if they met criteria for diagnosis of substance abuse or dependence other than caffeine in the past month by self-report or tested positive on a salivary drug screen for phenylcyclidine (PCP), tetrahydrocannabinol (THC), cocaine, opiates, methamphetamine, amphetamine (Accutest Saliva Test ${ }^{\mathrm{TM}}$, JANT Pharmacal Corporation, Encino, CA, USA) or alcohol (ALCO Screen, CHEMATICS, Inc., North Webster, IN, USA). Other exclusion criteria for both schizophrenia and control groups were lifetime diagnosis of cognitive impairment secondary to head injury, dementia or general medical illness, use of investigational medication in the past month, current diagnosis of major depressive disorder, current unstable medical illness including hypertension or ischemic heart disease, or a known allergy to constituents of the nicotine patch. Individuals with schizophrenia were excluded if there was evidence of recent deterioration in their mental state such as a change in nature or severity of symptoms documented in their medical record or if dose or type of psychiatric medication had been changed in the preceding month. Controls were excluded if they met lifetime criteria for any Axis-1 diagnosis on Structured Clinical Interview for DSM-IV (SCID) (First et al, 1995) or had a first-degree relative with a schizophrenia spectrum disorder.

\section{Procedure}

Following screening and enrollment, participants attended a total of three visits (a baseline visit followed by 2 study days). At the first visit, all subjects underwent a training session in the Cognitive Drug Research (CDR) battery (Simpson et al, 1991) (data not presented) and subjects with schizophrenia completed baseline clinical scales including the Scale for Assessment of Negative Symptoms (SANS) (Andreasen, 1981) and Positive and Negative Syndrome Scale (PANSS) (Kay, 1991). After this baseline visit, subjects were randomized using a computer-generated random number sequence to one of the two groups to determine 
the order for receipt of active and placebo patches. All subjects then attended the 2 study days separated by 1-2 weeks. Randomization was concealed using opaque envelopes, and assessors and subjects were blinded to group allocation. Female subjects underwent testing during the follicular phase of the menstrual cycle to avoid confounding effects of stage of menstrual cycle on cognitive performance (Symonds et al, 2004).

On both study days, participants completed exhaled-air $\mathrm{CO}$ measures and salivary drug and alcohol screens prior to a cognitive battery. Participants were instructed to abstain from caffeine for at least $1 \mathrm{~h}$ prior to all testing sessions. On completion of the 2-h cognitive battery, two $7 \mathrm{mg}$ nicotine (Nicoderm $\mathrm{CQ}^{\mathrm{TM}}$, Alza Corporation, Mountain View, CA, USA) or identical placebo patches (Alza Corporation) were applied to the upper arm. Participants remained in the study center while wearing the patch. They had lunch and watched a movie of their choice during this time. Three hours following patch application, subjects had a repeat expired-air $\mathrm{CO}$ measurement to rule out recent surreptitious smoking and repeated the cognitive battery. After the cognitive assessment, samples were collected for serum nicotine measurement. Blood samples for nicotine analysis (ABS Laboratories, London, UK) were collected in heparinized tubes and centrifuged for $10 \mathrm{~min}$ prior to being frozen at $-80^{\circ} \mathrm{C}$. Patches were removed following the blood draw, and medication side effects were recorded using an adverse events tracking form.

\section{Neuropsychological Measures}

Continuous performance test identical pairs version. The primary outcome measure was attention as measured by the Continuous Performance Test Identical Pairs (CPT-IP) Version 4.0 (Biobehavioral Technologies, New York, USA), developed for use in patients with schizophrenia and normal controls (Cornblatt et al, 1988, 1989). In this task, participants were asked to respond when two identical pairs of numbers were presented in sequence by pressing a mouse key as quickly as possible using the dominant hand. After 25 practice trials, three blocks of 150 trials were presented with a constant rate of one stimulus per second and stimulus duration of $50 \mathrm{~ms}$. The stimuli were presented with increasing cognitive load in successive blocks: two-, three- and four-digit target in the first, second and third block, respectively. Standard outcome variables on the CPTIP are the $\mathrm{d}^{\prime}$ measure of signal to noise, correct hits, hit reaction time, standard deviation of hit reaction time and errors of commission: false alarms and random errors. False alarms are a type of commission errors in which the stimulus presented was similar but not identical to the stimulus preceding it. Random errors are another type of commission errors in which the stimulus presented had no similarity to the previous stimulus.

Three card stroop. This standard test of visual attention, processing speed and cognitive interference was performed (Golden and Freshwater, 1998), in which three cards (Stoelting Co., Wood Dale, IL, USA) were presented in order: the first card with color names, the second with colored patches of ink and the third with color names printed in incongruously colored ink. Participants were asked to read or name as many colors as possible in $45 \mathrm{~s}$ for each condition. The raw interference score was calculated by subtracting the predicted color-word score (calculated using raw word and color scores) from the observed raw color-word score. This value was converted to an interference $T$ score by referring to a standardized table (Golden and Freshwater, 1998). A higher interference $T$ score indicates better task performance with less interference.

Letter number sequencing (LNS). This measure of working memory and auditory attention was performed under two conditions. In the first condition, participants were read progressively longer lists of letters and numbers and instructed to repeat these exactly as given, without reordering (Gold et al, 1997). In the second condition, participants were read progressively longer lists of numbers and letters and instructed to re-order the list and give the numbers first in ascending order and then the letters in alphabetical order (WMS-III) (Wechsler, 1997b). The sum of the trial scores provided the item score and the sum of the item scores provided the total score.

The Grooved Pegboard (model 32025 Lafayette Instrument Company, Lafayette, IN, USA). In this test of lateralized psychomotor speed, participants had $45 \mathrm{~s}$ to place as many pegs as possible into grooves on a board using their dominant hand. The number of correctly placed pegs and number of drops were recorded for each of the two trials.

Two additional cognitive measures were included in the battery. A measure of verbal memory was performed on a subset of the participants (Weiss et al, 2006) and the CDR battery was piloted, data not presented.

\section{Statistical Analysis}

Baseline demographic and clinical variables were compared using independent Student's $t$-tests or exact tests. Data were analyzed using a split-plot repeated measures analysis of variance (ANOVA) with time (pre-dose $v s$ post-dose) and treatment (nicotine $v s$ placebo) as within-subject factors, and diagnosis (schizophrenia $v s$ control) as between subject factors. Variables were assessed for distributional properties. Only one variable (proportion of random errors on the CPT-IP), was found to be substantially skewed and was subjected to a log transformation as follows (Cornblatt et al, 1988): the proportion of errors was multiplied by 100 , added to one and converted to natural logs (pre-transformation skew $=3.62(0.16)$, kurtosis $=15.00(0.31)$; post-transformation skew $=1.28(0.15)$, kurtosis $=1.36(0.31)$. The effect of order of active treatment, subject age, smoking history, and intelligence quotient (IQ) on pre- $v s$ post-dose cognitive measures was investigated using bivariate correlations and included as a covariate in analyses if significant. Separate additional analyses were also performed to assess the effect of treatment on attentional performance with increasing cognitive load across the three blocks on the CPT-IP, by including block (2-, 3- and 4-digit) as a within-group factor in the repeated measures ANOVA described above. Effect sizes were measured using partial $\eta^{2}$ for the ANOVAs. Data are presented as mean \pm standard deviation (SD). 
All analyses were performed using SPSS for Windows 10 (SPSS Inc.).

\section{RESULTS}

Fifty-six individuals with schizophrenia and 288 controls responded to recruitment fliers and underwent initial telephone screening. Eighteen patients with schizophrenia were excluded during initial screening. Six were not interested, two were outside the eligible age range, two were current smokers or using NRT and eight did not meet diagnostic criteria for participation. Two hundred and thirty-five controls were excluded during initial telephone screening. One hundred and thirty-two were not interested after full study procedures and remuneration were explained; 90 reported past or current psychiatric disorder; seven were current smokers and six were excluded for other reasons including current significant physical illness. Thirty-eight potential participants with schizophrenia and 53 controls met the initial criteria, signed informed consent, and underwent further screening. Of these, six with schizophrenia were ineligible and four withdrew the consent, and 16 controls were ineligible and five withdrew the consent. Twenty-eight subjects with schizophrenia and thirty-two controls met full criteria for participation and were randomized for order of receiving nicotine and placebo patches.

Compared with subjects with schizophrenia, controls were younger and less likely to have smoked in the past (Table 1). As expected, baseline education and IQ were higher, and baseline cognitive performance (at the first predose testing session) was significantly better in controls compared with subjects with schizophrenia on all cognitive tests (see Supplementary Table 1). All participants with schizophrenia and no controls were taking psychotropic medications (Table 2). Twenty-nine participants consented to have blood drawn for serum nicotine at the end of each testing session. Nicotine plasma levels were $7.4(3.8) \mathrm{ng} / \mathrm{ml}$ following the active patch administration and $0.3(0.5) \mathrm{ng} / \mathrm{ml}$ following placebo administration $(t=-9.8, p<0.0001)$. Serum nicotine levels did not differ between the schizophrenia and control groups in the active patch condition $(t=-0.3, p=0.8)$ or placebo condition $(t=-0.9, p=0.4)$ (Table 3). Mean duration of patch application was 5.3 $(0.3) \mathrm{h}$ for subjects with schizophrenia and $5.1(0.3) \mathrm{h}$ for controls $(t=2.6, p=0.01)$. The average time between the 2 study days was 11.1 (11.6) days in controls and 8.9 (3.0) days in the schizophrenia group $(t=-1.1, p=0.3)$.

\section{Cognitive Measures}

Neither the order of active drug administration, subject age, smoking history nor the IQ was found to correlate with difference between pre- and post-dose performance on any of the neurocognitive variables, and therefore, was not included in the models.

Results of the repeated measures ANOVA, including effect sizes, are given in Table 3. On the CPT-IP, nicotine treatment improved performance in both groups by reducing hit reaction time (time $\times$ treatment interaction $\mathrm{F}_{1,58}=20.35, p<0.0001$ ), SD of hit reaction time (timetreatment $\mathrm{F}_{1,58}=8.23, p=0.006$ ) and random errors (timetreatment $\left.\mathrm{F}_{1,58}=13.23, p<0.001\right)$. Nicotine administration resulted in a greater reduction in commission errors in those with schizophrenia $v s$ controls, with a significant time $\times$ treatment $\times$ diagnosis interaction for false alarms $\left(\mathrm{F}_{1,58}=7.58, p<0.01\right)$ and random errors $\left(\mathrm{F}_{1,58}=5.41\right.$, $p=0.02$ ) (Table 3, Figure 1a and b, Supplementary Figure $a$ and $b$ ). Nicotine did not significantly improve the performance on $d^{\prime}$ (time $\times$ treatment $\mathrm{F}_{1,58}=2.24, p=0.14$ ) and had no effect on the number of correct hits on the CPTIP (time $\times$ treatment $\mathrm{F}_{1,58}=0.13, p=0.72$ ). As expected, there was a main effect of diagnosis on all CPT-IP variables (reaction time $\mathrm{F}_{1,58}=40.09, p<0.0001$; reaction time $\mathrm{SD}$

Table I Baseline Characteristics

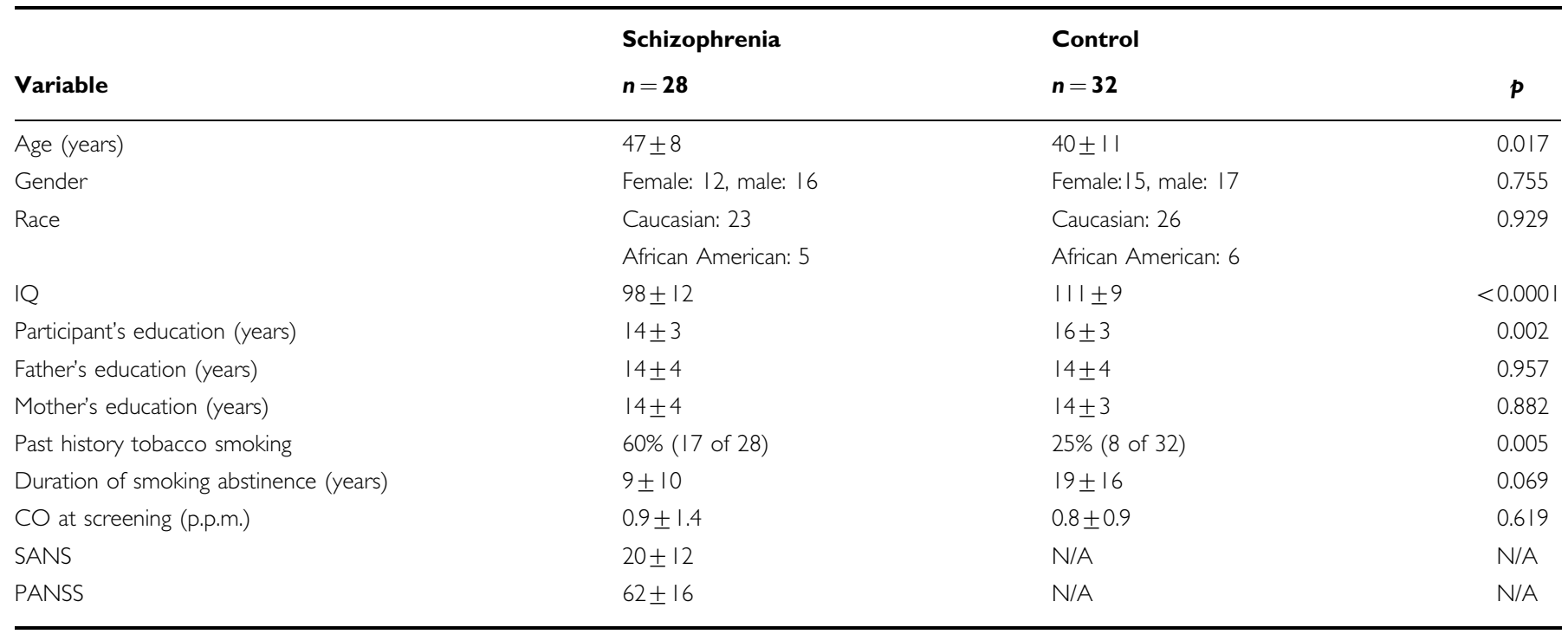

Abbreviations: CO, carbon monoxide; SANS, Scale for Assessment of Negative Symptoms; PANSS, Positive and Negative Syndrome Scale. $p$-values based on two-sample Student's $t$-tests for continuous variables and Exact tests for binary variables. 
There were no significant effects of treatment or interaction between variables on the LNS or Grooved Pegboard (Table 3). A significant main effect of diagnosis was observed for both tasks (LNS without reorder $\mathrm{F}_{1,58}=12.94, p<0.001$; LNS with reorder $\mathrm{F}_{1,58}=24.00$, $p<0.0001$; Grooved Pegboard $\mathrm{F}_{1,56}=33.11, p<0.0001$ ).

\section{Adverse Events}

All subjects attended both patch administration visits. Two participants with schizophrenia experienced serious adverse events judged to be unrelated to study participation. One subject required hospitalization for an allergic reaction to peanuts prior to study visits and later completed the study. A second subject was hospitalized due to deterioration in mental state 28 days after study visits were completed. One subject with schizophrenia and two controls were unable to complete the entire post dose neurocognitive battery due to the development of nausea and vomiting. Data for the Letter Number Sequencing Task and CPT-IP were obtained from these subjects, as these tasks had been completed prior to the development of symptoms. Data were not collected for the Stroop (all three subjects) and Grooved Pegboard (two subjects) and these participants were, therefore, excluded from the analyses of these measures. Two subjects with schizophrenia and four controls required dose reduction to $7 \mathrm{mg}$ after experiencing moderate nausea. Mild adverse events included minor skin irritations (17 subjects), dizziness (14 subjects), headache (11 subjects), mild nausea (seven subjects), or palpitations (seven subjects). Subjects who required dose reduction were included in all analyses, although it is possible that the lowering of dose may have reduced any effects of nicotine. The experience of adverse effects may have reduced the therapeutic effect of nicotine, however, in bivariate analyses there was no significant correlation between total number or severity of adverse effects and the effect of nicotine on any neurocognitive variable.

\section{DISCUSSION}

$p<0.0001 ; \mathrm{d}^{\prime} \mathrm{F}=49.6, p<0.0001$; false alarms $\mathrm{F}_{1,58}=$ $15.02, p<0.001$; correct hits $\mathrm{F}_{1,58}=49.2, p<0.0001$ ), indicating impaired performance in schizophrenia $v s$ controls. There were no significant interactions between digit block and treatment on any CPT-IP variables to suggest greater benefit of nicotine with greater cognitive load on this task.

In the Stroop task, there was a significant time $\times$ treatment $\times$ diagnosis interaction $\left(\mathrm{F}_{1,55}=4.87, p=0.03\right)$, indicating that nicotine improved the interference $T$-score in schizophrenia but not in controls (Table 3, Figure 1c, Supplementary Figure c). Analysis of raw scores for each of the Stroop conditions confirmed the improvement in performance in subjects with schizophrenia was occurring in the color-word condition of the Stroop (time $\times$ treatment $\times$ diagnosis interaction $\left.\mathrm{F}_{1,55}=3.52, p=0.06\right)$ and not in the word (time $\times$ treatment $\times$ diagnosis interaction $\mathrm{F}_{1,55}=1.05, p=0.31$ ) or color conditions (time $\times$ treatment $\times$ diagnosis interaction $\mathrm{F}_{1,55}=0.66, p=0.42$ ). The significant main effect of diagnosis $\left(F_{1,55}=19.12\right.$, $p<0.0001)$ on interference $T$-score indicated impaired performance in schizophrenia compared with controls.
A single dose of transdermal nicotine improved the attentional performance in nonsmokers with schizophrenia and healthy control participants as measured by hit reaction time, reaction time variability and random errors on the CPT-IP. Additionally, nicotine reduced commission errors as measured by false alarms and random errors on the CPTIP and improved performance on the interference condition of the Stroop in those with schizophrenia to a greater extent than in controls. Beneficial effects of nicotine on sustained attention, vigilance and response inhibition were not accompanied by improvements in simple auditory attention, working memory or psychomotor speed, as no improvement was observed on the LNS or grooved pegboard. These findings are supportive of our primary hypothesis that nicotine administration would result in improved attentional performance compared with placebo in nonsmokers with schizophrenia and controls, and lend partial support to our secondary hypothesis that individuals with schizophrenia would derive greater attentional benefits from nicotine than normal controls. These findings are 
Table 3 Results of Repeated Measures ANOVA

\begin{tabular}{|c|c|c|c|c|c|c|c|c|c|c|c|c|c|c|}
\hline \multirow[b]{3}{*}{ Measure } & \multicolumn{4}{|c|}{ Schizophrenia } & \multicolumn{4}{|c|}{ Control } & \multicolumn{6}{|c|}{ ANOVA } \\
\hline & \multicolumn{2}{|c|}{ Nicotine } & \multicolumn{2}{|c|}{ Placebo } & \multicolumn{2}{|c|}{ Nicotine } & \multicolumn{2}{|c|}{ Placebo } & \multicolumn{3}{|c|}{ Time $\times$ treat } & \multicolumn{3}{|c|}{ Time $\times$ treat $\times$ diag } \\
\hline & Pre-drug & Post-drug & Pre-drug & Post-drug & Pre-drug & Post-drug & Pre-drug & Post-drug & $F(\text { d.f. })^{a}$ & $p$ & $\mathbf{E S}^{\mathbf{b}}$ & $F(d f)^{a}$ & $p$ & ES \\
\hline \multicolumn{15}{|l|}{$\overline{\text { CPT-IP }}$} \\
\hline$d^{\prime}$ & $2.0(0.8)$ & $2.2(0.8)$ & $2.2(0.8)$ & $2.1(0.8)$ & $3.4(0.6)$ & $3.4(0.6)$ & $3.2(0.7)$ & $3.2(0.6)$ & $2.2(1,58)$ & 0.14 & 0.04 & ।.I $(1,58)$ & 0.30 & 0.02 \\
\hline Hits (number) & $21.2(4.8)$ & $21.8(6.1)$ & $21.9(5.1)$ & $22.0(5.2)$ & $28.5(4.6)$ & $28.5(1.7)$ & $27.7(2.0)$ & $27.5(3.1)$ & $0.1(1,58)$ & 0.72 & $<0.01$ & $0.02(1,58)$ & 0.90 & $<0.01$ \\
\hline HRT (ms) & $582(74)$ & $542(100)$ & $562(82)$ & $569(78)$ & $480(55)$ & $453(50)$ & $463(43)$ & $465(45)$ & $20.4(1,58)$ & $<0.001$ & 0.26 & I.I $(1,58)$ & 0.30 & 0.02 \\
\hline SD HRT (ms) & $159(37)$ & $142(38)$ & $147(32)$ & $149(32)$ & $100(27)$ & $88(26)$ & $97(24)$ & $99(3 \mid)$ & $8.2(1,58)$ & 0.01 & 0.12 & $0.3(1,58)$ & 0.57 & $<0.01$ \\
\hline False alarms (number) & $3.9(2.8)$ & $3.0(2.0)$ & $3.3(1.7)$ & $3.9(2.7)$ & ।.7 (1.5) & $1.9(1.3)$ & $2.1(1.5)$ & $1.9(1.3)$ & $2.5(1,58)$ & 0.12 & 0.04 & $7.6(1,58)$ & 0.01 & 0.12 \\
\hline Ln RE & $1.3(0.8)$ & $1.0(0.8)$ & I.I (0.6) & $1.2(0.8)$ & $0.3(0.3)$ & $0.2(0.2)$ & $0.3(0.4)$ & $0.3(0.4)$ & |3.2(1,58) & $<0.001$ & 0.18 & $5.4(1,58)$ & 0.02 & 0.08 \\
\hline Stroop interference $T$-score & $48.3(5.9)$ & $50.4(5.8)$ & $49.6(4.8)$ & $49.0(4.6)$ & $56.5(7.0)$ & $56.8(10.3)$ & $56.8(10.0)$ & $58.8(10.0)$ & $0.2(1,55)$ & 0.65 & $<0.01$ & $4.9(1,55)$ & 0.03 & 0.08 \\
\hline LN (number) W/O reorder & $12.6(3.4)$ & $12.6(3.3)$ & $12.9(2.8)$ & $12.5(3.4)$ & I5.5 (3.4) & I $5.5(3.3)$ & I $5.4(3.7)$ & $15.9(3.4)$ & $0.02(1,58)$ & 0.89 & $<0.0$ I & $1.4(1,58)$ & 0.25 & 0.02 \\
\hline With reorder & $8.7(3.1)$ & $8.8(3.1)$ & $8.4(2.9)$ & $9.0(2.6)$ & $12.3(3.0)$ & $12.2(3.4)$ & $12.3(3.4)$ & $12.6(3.1)$ & $2.2(1,58)$ & 0.14 & 0.04 & $0.1(1,58)$ & 0.75 & $<0.01$ \\
\hline Pegboard (number of pegs) & | 3.6 (3.8) & | $4.4(3.6)$ & | $3.2(3.7)$ & $14.5(3.2)$ & | $8.8(5.5)$ & I9.1 (3.2) & | $8.6(2.5)$ & | $8.6(2.7)$ & $0.1(1,56)$ & 0.76 & $<0.01$ & $0.4(1,56)$ & 0.50 & $<0.01$ \\
\hline Serum nicotine $(\mathrm{ng} / \mathrm{ml})$ & $N / A$ & $7.2(5.3)$ & $N / A$ & $0.2(0.2)$ & $N / A$ & $7.6(2.2)$ & $N / A$ & $0.4(0.7)$ & & & $N / A$ & & & $N / A$ \\
\hline
\end{tabular}

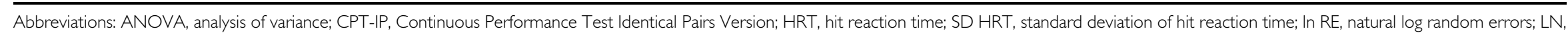
letter number sequencing task; W/O reorder, without reorder; Pegboard, grooved pegboard; Treat, treatment; Diag, diagnosis.

Pre- and post-dose values in CPT-IP are average values of all digit blocks.

Each number refers to mean \pm standard deviation.

${ }^{a} \mathrm{~F}$ values refer to results of repeated measures ANOVA with time (pre- vs post-drug) and treatment (nicotine vs placebo) as within-group factors and diagnosis (schizophrenia vs controls) as between-group factors. ${ }^{\mathrm{b}} \mathrm{ES}=$ Effect size using partial $\eta^{2}$ 

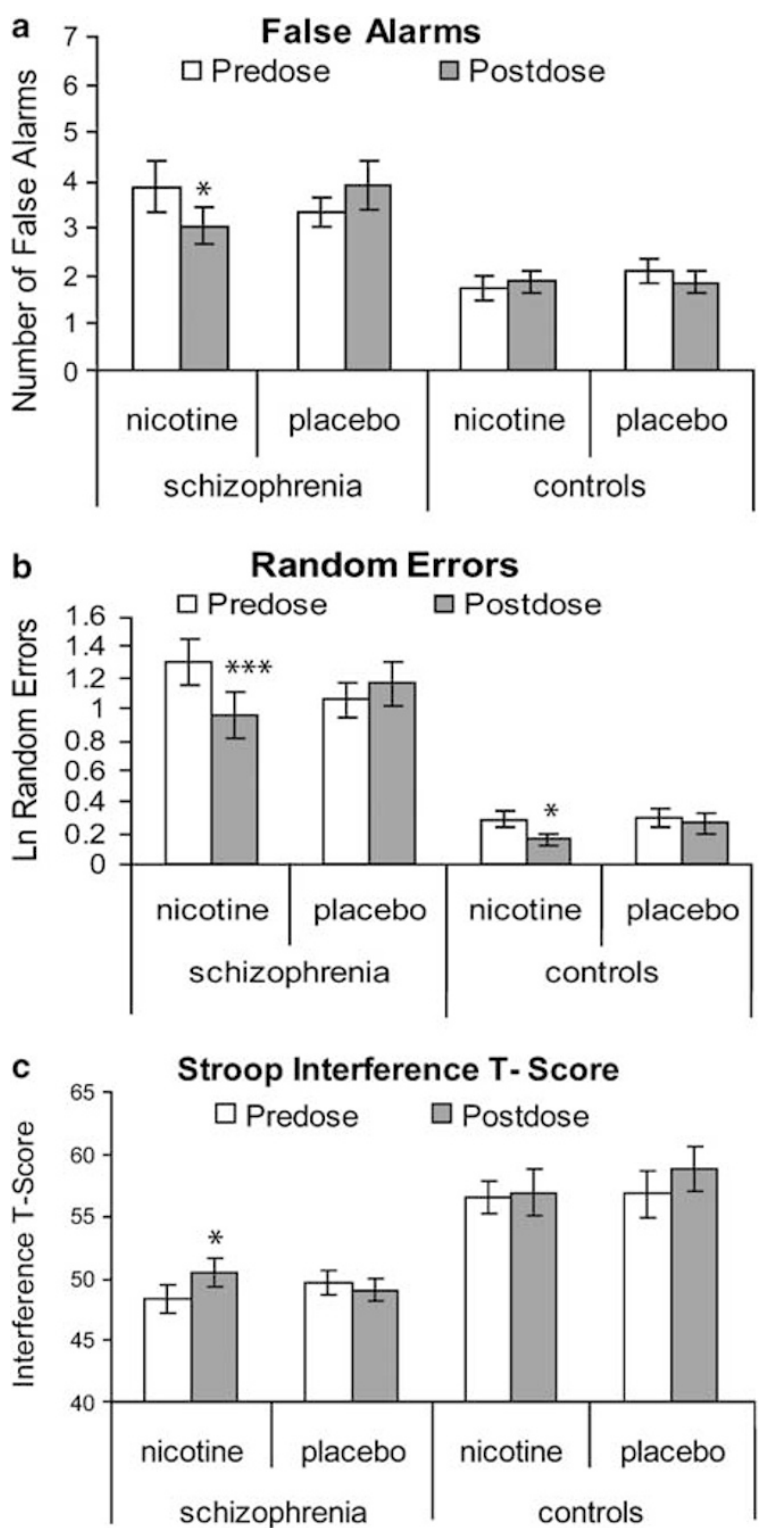

Figure I (a) False alarms. (b) Random errors. (c) Stroop interference T score. Nicotine administration was associated with greater reduction in false alarms (a) and random errors (b) on the CPT-IP and improvement in Stroop interference T-score (c) in subjects with schizophrenia than controls. There was a time $\times$ treatment $\times$ diagnosis interaction for false alarms $(p=0.008)$, random errors $(p=0.02)$ and Stroop interference T-score $(p=0.03)$. Data are presented as means \pm standard error. $* p \leqslant 0.05$ for pre- vs post-dose paired t-tests. $* * * 0.001$.

consistent with a disease-specific benefit of nicotine on impulsivity and response inhibition.

Our findings are consistent with other studies that have demonstrated improvement in pre-attentional and attentional tasks with nicotine administration in individuals with schizophrenia (Adler et al, 1993; Levin et al, 1996b; Kumari et al, 2001; Depatie et al, 2002; Sherr et al, 2002; Olincy et al, 2003; Harris et al, 2004; Jacobsen et al, 2004; Smith et al, 2006). Two previous studies investigated the effects of nicotine on attention in schizophrenia using the CPT-IP (Depatie et al, 2002; Sherr et al, 2002). In one study (Depatie et al, 2002), a $14 \mathrm{mg}$ nicotine patch application improved the number of correct hits to a greater extent in smokers with schizophrenia than in controls. We found no effect of nicotine on correct hits, however, a high correct-hit rate at baseline in our sample may have contributed to the difference in findings in the two studies. In another study (Sherr et al, 2002), in a group of smokers and nonsmokers with and without schizophrenia, nicotine, delivered via nasal spray, improved eye acceleration in the SPEM task in subjects with schizophrenia, however had no effect on CPTIP $d^{\prime}$, while other CPT-IP variables were not reported from this study. Variation in these findings may be due to pharmacological differences such as dose or mode of administration of nicotine or to differences such as in smoking status or psychiatric medication of participants.

Previous studies investigating the effects of nicotine on attention in nonsmokers without psychiatric disorder have yielded inconsistent findings (Heishman et al, 1993; Le Houezec et al, 1994; Foulds et al, 1996; Levin et al, 1998; Heishman and Henningfield, 2000; Ernst et al, 2001; Mumenthaler et al, 2003; Sacco et al, 2004). Although it has been suggested that individuals with optimal baseline performance may experience deterioration in performance with nAChR stimulation unless task demands are very high (Newhouse et al, 2004), variation in findings may also be attributed to differences in the measure used to assess attentional performance or, as above, to pharmacological differences such as dose or mode of administration of nicotine. One study which investigated the effect of a single dose of transdermal nicotine in nonsmokers, with attention as the primary outcome, described improvement in performance on the Conners' CPT as reflected by a reduction in hit reaction time variability and omission errors, however, no medication effect was seen on commission errors (Levin et al, 1998). Our results with a different $\mathrm{CPT}$ and a higher dose of nicotine, are consistent although not identical with these results and provide further evidence that nicotinic receptor stimulation leads to cognitive benefits in individuals without cognitive impairment (Le Houezec et al, 1994; Foulds et al, 1996; Levin et al, 1998; Mumenthaler et al, 2003).

In addition to the effects described above, nonsmokers with schizophrenia improved more than controls on commission errors (false alarms and random errors) on the CPT-IP and on Stroop performance. This reduction in commission errors was not accompanied by a decrease in the number of correct hits, indicating that this finding was specific for reduction in impulsive errors rather than an effect on overall response tendencies. The number of false alarms in the control group suggests that the interaction on this variable is not merely due to 'floor effects' in the control group. Controls made very few random errors on the CPTIP, raising the possibility that floor effects contributed to the observed treatment by diagnosis interaction on this variable. We conducted a one-sample $t$-test, which confirmed that the number of random errors in the control group was significantly greater than zero at baseline, reducing the likelihood that a floor effect contributed to this observation. There was also a greater reduction in false alarms in subjects with schizophrenia compared with controls on a verbal memory task performed in a subset of our sample with no improvement in hit rate or source memory (Weiss et al, 2006). These findings are consistent 
with those of Myers and coworkers who reported that nicotine nasal spray reduced false alarms in smokers and nonsmokers with schizophrenia on a delayed recognition task, although this was also accompanied by a reduction in hit rate in the nonsmokers not seen in the present study (Myers et al, 2004).

While we expected an interaction on all attention measures, we observed a greater effect of nicotine in individuals with schizophrenia compared with controls on aspects of attentional function that may be mediated via an improvement in response inhibition, which refers to the ability to suppress inappropriate responses (Jentsch and Taylor, 1999). These findings are analogous to improvements following nicotine administration demonstrated using a number of experimental paradigms that reflect inhibitory functioning such as auditory p50 gating, PPI and eye movement tasks (Adler et al, 1993; Kumari et al, 2001; Depatie et al, 2002; Olincy et al, 2003; Postma et al, 2006). The effects of nicotine on auditory P50 gating appears to be due to activation of the $\alpha 7 \mathrm{nAChR}$, which may facilitate inhibition in the hippocampus via activation of GABAergic interneurons (Freedman et al, 1994; Hershman et al, 1995; Leonard et al, 1996). Nicotine effects on response inhibition in this study could also be mediated by enhancement of dopaminergic functioning. The dopaminergic system is believed to modulate a range of cognitive processes, including response inhibition (Brozoski et al, 1979; Mehta et al, 1999; Cropley et al, 2006). Both the striatum (especially the caudate) and prefrontal cortex have been identified as regions important for response inhibition (Lawrence et al, 1998; Volkow et al, 1998, 2004; Aron and Poldrack, 2005; Cropley et al, 2006). Impaired response inhibition has frequently been described in schizophrenia (Roberts and Pennington, 1996; Badcock et al, 2002; Henik et al, 2002) and is associated with abnormal striatal activation in both those with schizophrenia and their first-degree relatives (Vink et al, 2006). Deficient nAChR function in the cortex and caudate, with abnormal upregulation of $\alpha 4 \beta 2 \mathrm{nAChR}$ 's in these regions, have also been described in schizophrenia (Breese et al, 2000; Durany et al, 2000). Nicotine administration may ameliorate deficits in response inhibition in individuals with schizophrenia more than controls by augmenting deficient nAChR function, thereby increasing dopaminergic activity in regions important for this process.

While an improvement in response inhibition is the most likely explanation for the time $\times$ treatment $\times$ diagnosis interactions observed in this study, it is also possible that other cognitive mechanisms may have played a role. If effect of nicotine on commission errors had been mediated by improvements in stimulus encoding and/or working memory, we would have expected greater effects of nicotine in blocks with a greater number of digits in the CPT-IP and LNS tasks, which was not observed. We would also have expected greater improvements in CPT-IP correct hit rate if stimulus encoding and working memory mediated the effect of nicotine, although high correct hit rates at baseline in both groups may have resulted in ceiling effects on this variable. Furthermore, nicotine improved performance in the interference condition of the Stroop and failed to improve performance on the word naming and color naming condition, indicating that improvement on this task was not mediated by improved processing speed and visual attention.

There are limitations of our study that deserve specific mention. First, we chose to investigate the effects of nicotine in nonsmokers and excluded smokers to avoid the confounding effects of nicotine withdrawal and reversal effects on outcome measures. Findings in nonsmokers with schizophrenia may not generalize to smokers with schizophrenia because smokers with schizophrenia may have pathophysiological differences compared with nonsmokers, including more severe disease (Goff et al, 1992; McEvoy et al, 1999). Individuals with schizophrenia who are able to quit smoking appear to be less cognitively impaired than those who are unable to quit smoking (Dolan et al, 2004; Evins et al, 2005a). Specifically, better performance in CPT reaction time variability has been shown to predict abstinence in smoking cessation studies in those with schizophrenia (Evins et al, 2005a), indicating that exsmokers with schizophrenia may have less cognitive impairment than smokers. Secondly, the control group was significantly younger, had a higher mean IQ and lower rate of previous smoking than the schizophrenia group. We found no correlation between age, IQ or smoking history with medication effect on any measure. In addition, we repeated all analyses excluding eight control subjects who were not matched on the basis of age and sex and found that all interactions remained significant. The lack of correlation between smoking history and medication effect is important as impairments in inhibitory function resulting from frontostriatal dysfunction have been described in chronic drug abuse (Jentsch and Taylor, 1999; Volkow et al, 2004). Furthermore, in a recent study in smokers without psychiatric disorder, smoking abstinence resulted in impairments in response inhibition that were reversed by nicotine administration (Dawkins et al, 2007). The lack of correlation between smoking history and medication effect suggests that the effect of nicotine on response inhibition in schizophrenia is unlikely to be explained by a greater number of ex-smokers compared with controls. Thirdly, the duration of patch application also differed between the control and schizophrenia groups, as many more controls participated in the study after one task had been removed from the cognitive battery. This was the final task in the battery measuring verbal memory and is reported separately (Weiss et al, 2006). As this discontinued task was at the very end of the testing period, prior to removal of the patch, the timing of the other cognitive tasks did not change. This could have had an effect on serum nicotine levels at the end of intervention but would not have had an effect on cognitive measurements. Finally, those with schizophrenia were treated with various psychotropic medications. Several participants were treated with medications such as haloperidol that may cause dose-dependent attentional impairment that is reversible by nicotine (Levin et al, 1996b). In these subjects, the effect of nicotine may have been reversal of cognitive effects of D2 blockade rather than improvement of disease-specific attentional deficits. However, in this study, few participants were treated with classic D2 blocking antipsychotics, while many were treated with psychiatric medications such as clozapine, bupropion, or fluoxetine that may attenuate the effects of nicotine. Nine subjects were treated with the atypical antipsychotic, 
clozapine, which has been shown to attenuate the effects of nicotine on both working memory and attentional performance in animal models of schizophrenia (Addy et al, 2005; Rezvani et al, 2007). Seven participants were treated with either bupropion or fluoxetine, which have been shown to have nicotinic antagonist properties in vitro (Hennings et al, 1997; Slemmer et al, 2000). While it was not possible to investigate the effects of nicotine in medication-free patients due to ethical considerations, excluding participants who were treated with clozapine, bupropion or fluoxetine may have resulted in greater benefits of nicotine being observed in the schizophrenia group.

To our knowledge, this is the largest study of the effects of nicotine on cognitive function in nonsmokers with and without schizophrenia. Our findings suggest that the nicotinic receptor system plays a role in attention in both healthy controls and individuals with schizophrenia. Our findings also suggest that nicotine may have additional benefit in schizophrenia by ameliorating deficits in response inhibition. This study demonstrates that nicotine has an effect on attentional processes and response inhibition independent of its effects on reversing symptoms of nicotine withdrawal in controls and individuals with schizophrenia. However, the clinical significance of such improvements on neuropsychological test performance following administration of a single dose of nicotine is unclear. The effect sizes described here are modest. However, modest improvements in performance on neuropsychological tests in individuals with cognitive impairments may translate into improvement in functional outcomes, and this would need to be assessed. Additionally, nicotine induces tachyphylaxis (Harris et al, 2004; Martin et al, 2004) and effects of repeated dosing would need to be investigated. Exploration of other $\mathrm{nAChR}$ agonists that may exhibit less tachyphylaxis may hold more promise for the treatment of cognitive deficits in schizophrenia (Olincy et al, 2006).

In summary, we describe in this study that a single $14 \mathrm{mg}$ dose of transdermal nicotine improved the attentional performance in nonsmokers with schizophrenia and normal controls. Additionally, we found greater improvements in CPT-IP errors of commission and Stroop performance in patients with schizophrenia than controls. Investigation of the effects of repeated administration of nicotinic agonists on functional outcomes is needed to investigate further the therapeutic potential of nicotinic agonists in the treatment of schizophrenia.

\section{ACKNOWLEDGEMENTS}

This work was supported by K23 DA00510 (AE) and by a Clinical Trial Research Grant from the Stanley Medical Research Institute (AE). We thank Dr Deborah Blacker for assistance with the study design and Dr David Schoenfeld for consultation on statistical analysis.

\section{DISCLOSURE/CONFLICTS OF INTEREST}

Dr Goff has received research funding and serves on the advisory board of GlaxoSmithKline who are licensed to use the Nicoderm CQ trademark. In addition, he has received research funding from Janssen Pharmaceuticals, Pfizer Inc., Bristol Meyer Squibb, and Cephalon and honoraria from Eli Lilly and Company, Janssen Pharmaceuticals, Pfizer Inc., and Bristol Myer Squibb. He is also a member of the DSMB for Wyeth and serves on the advisory board of Janssen Pharmaceuticals, Pfizer Inc., Bristol Meyer Squibb, Merck, Solvay Pharmaceuticals, and AstraZeneca Pharmaceuticals.

Dr Evins has also received grant support from Glaxo SmithKline to support a collaborative U01 funded by NIDA and also received grant support from Janssen Pharmaceuticals and AstraZeneca.

Dr Mufti's fellowship was supported by the Ministry of Education, Saudi Arabia.

Ms Jubelt has received research support from the Doris Duke Charitable Foundation.

Dr Weiss has received speaker's honoraria from Solvay Pharmaceuticals Inc.

Dr Freudenreich has received grant research funding from Pfizer.

Dr Barr, Ms Culhane, Dr Deckersbach, Mr Dyer, and Dr Kelly have no relevant financial interests to disclose.

\section{REFERENCES}

Addy NA, Pocivavsek A, Levin ED (2005). Reversal of clozapine effects on working memory in rats with fimbria-fornix lesions. Neuropsychopharmacology 30: 1121-1127.

Adler LE, Hoffer LD, Wiser A, Freedman R (1993). Normalization of auditory physiology by cigarette smoking in schizophrenic patients. Am J Psychiatry 150: 1856-1861.

Adler LE, Hoffer LJ, Griffith J, Waldo MC, Freedman R (1992). Normalization by nicotine of deficient auditory sensory gating in the relatives of schizophrenics. Biol Psychiatry 32: 607-616.

Andreasen NC (1981). Scale for the Assessment of Negative Symptoms (SANS). University of Iowa: Iowa City.

Aron AR, Poldrack RA (2005). The cognitive neuroscience of response inhibition: relevance for genetic research in attentiondeficit/hyperactivity disorder. Biol Psychiatry 57: 1285-1292.

Avila MT, Sherr JD, Hong E, Myers CS, Thaker GK (2003). Effects of nicotine on leading saccades during smooth pursuit eye movements in smokers and nonsmokers with schizophrenia. Neuropsychopharmacology 28: 2184-2191.

Badcock JC, Michie PT, Johnson L, Combrinck J (2002). Acts of control in schizophrenia: dissociating the components of inhibition. Psychol Med 32: 287-297.

Breese CR, Lee MJ, Adams CE, Sullivan B, Logel J, Gillen KM et al (2000). Abnormal regulation of high affinity nicotinic receptors in subjects with schizophrenia. Neuropsychopharmacology 23: 351-364.

Brozoski TJ, Brown RM, Rosvold HE, Goldman PS (1979). Cognitive deficit caused by regional depletion of dopamine in prefrontal cortex of rhesus monkey. Science 205: 929-932.

Cornblatt BA, Lenzenweger MF, Erlenmeyer-Kimling L (1989). The continuous performance test, identical pairs version: II. Contrasting attentional profiles in schizophrenic and depressed patients. Psychiatry Res 29: 65-85.

Cornblatt BA, Risch NJ, Faris G, Friedman D, Erlenmeyer-Kimling L (1988). The Continuous Performance Test, identical pairs version (CPT-IP): I. New findings about sustained attention in normal families. Psychiatry Res 26: 223-238.

Cropley VL, Fujita M, Innis RB, Nathan PJ (2006). Molecular imaging of the dopaminergic system and its association with human cognitive function. Biol Psychiatry 59: 898-907. 
Dalack GW, Healy DJ, Meador-Woodruff JH (1998). Nicotine dependence in schizophrenia: clinical phenomena and laboratory findings. Am J Psychiatry 155: 1490-1501.

Dawkins L, Powell JH, West R, Powell J, Pickering A (2007). A double-blind placebo-controlled experimental study of nicotine: II-Effects on response inhibition and executive functioning. Psychopharmacology (Berl) 190: 457-467.

de Leon J, Diaz FJ, Rogers T, Browne D, Dinsmore L (2002). Initiation of daily smoking and nicotine dependence in schizophrenia and mood disorders. Schizophr Res 56: 47-54.

Depatie L, O'Driscoll GA, Holahan AL, Atkinson V, Thavundayil JX, Kin NN et al (2002). Nicotine and behavioral markers of risk for schizophrenia: a double-blind, placebo-controlled, crossover study. Neuropsychopharmacology 27: 1056-1070.

Dolan SL, Sacco KA, Termine A, Seyal AA, Dudas MM, Vessicchio JC et al (2004). Neuropsychological deficits are associated with smoking cessation treatment failure in patients with schizophrenia. Schizophr Res 70: 263-275.

Durany N, Zochling R, Boissl KW, Paulus W, Ransmayr G, Tatschner $\mathrm{T}$ et al (2000). Human post-mortem striatal alpha4beta2 nicotinic acetylcholine receptor density in schizophrenia and Parkinson's syndrome. Neurosci Lett 287: 109-112.

Ernst M, Heishman SJ, Spurgeon L, London ED (2001). Smoking history and nicotine effects on cognitive performance. Neuropsychopharmacology 25: 313-319.

Evins AE, Culhane MA, Deckersbach T, Cather C, Freudenreich O, Henderson DC et al (2005a). Predictors of Smoking Cessation in Patients with Schizophrenia. 11th Annual Meeting of the Society for Research on Nicotine and Tobacco, Prague, Czech Republic.

Evins AE, Deckersbach T, Cather C, Freudenreich O, Culhane MA, Henderson DC et al (2005b). Independent effects of tobacco abstinence and bupropion on cognitive function in schizophrenia. J Clin Psychiatry 66: 1184-1190.

First MB, Spitzer RL, Gibbon M, Williams JBW (1995). Structured Clinical Interview for DSM-IV Axis I Disorders-Patient Edition (SCID-I/P, Version 2.0). Biometrics Research Department, New York State Psychiatric Institute: New York.

Foulds J, Stapleton J, Swettenham J, Bell N, McSorley K, Russell MA (1996). Cognitive performance effects of subcutaneous nicotine in smokers and never-smokers. Psychopharmacology (Berl) 127: 31-38.

Freedman R, Adler LE, Bickford P, Byerley W, Coon H, Cullum CM et al (1994). Schizophrenia and nicotinic receptors. Harv Rev Psychiatry 2: 179-192.

Freedman R, Coon H, Myles-Worsley M, Orr-Urtreger A, Olincy A, Davis A et al (1997). Linkage of a neurophysiological deficit in schizophrenia to a chromosome 15 locus. Proc Natl Acad Sci USA 94: 587-592.

Freedman R, Hall M, Adler LE, Leonard S (1995). Evidence in postmortem brain tissue for decreased numbers of hippocampal nicotinic receptors in schizophrenia. Biol Psychiatry 38: 22-33.

George TP, Verrico CD, Picciotto MR, Roth RH (2000). Nicotinic modulation of mesoprefrontal dopamine neurons: pharmacologic and neuroanatomic characterization. J Pharmacol Exp Ther 295: 58-66.

George TP, Vessicchio JC, Termine A, Sahady DM, Head CA, Pepper WT et al (2002). Effects of smoking abstinence on visuospatial working memory function in schizophrenia. Neuropsychopharmacology 26: 75-85.

Glassman AH (1993). Cigarette smoking: implications for psychiatric illness. Am J Psychiatry 150: 546-553.

Goff DC, Henderson DC, Amico E (1992). Cigarette smoking in schizophrenia: relationship to psychopathology and medication side effects. Am J Psychiatry 149: 1189-1194.

Gold JM, Carpenter C, Randolph C, Goldberg TE, Weinberger D (1997). Auditory working memory and Wisconsin Card Sorting Test performance in schizophrenia. Arch Gen Psychiatry 54: $159-165$
Golden CJ, Freshwater SM (1998). The Stroop Color and Word Test: A Manual for Clinical and Experimental Uses. Stoelting Co.: Wood Dale, IL.

Green MF (1996). What are the functional consequences of neurocognitive deficits in schizophrenia? Am J Psychiatry 153: 321-330.

Green MF, Kern RS, Braff DL, Mintz J (2000). Neurocognitive deficits and functional outcome in schizophrenia: are we measuring the 'right stuff? Schizophr Bull 26: 119-136.

Harris JG, Kongs S, Allensworth D, Martin L, Tregellas J, Sullivan B et al (2004). Effects of nicotine on cognitive deficits in schizophrenia. Neuropsychopharmacology 29: 1378-1385.

Heishman SJ, Henningfield JE (2000). Tolerance to repeated nicotine administration on performance, subjective, and physiological responses in nonsmokers. Psychopharmacology (Berl) 152: 321-333.

Heishman SJ, Snyder FR, Henningfield JE (1993). Performance, subjective, and physiological effects of nicotine in non-smokers. Drug Alcohol Depend 34: 11-18.

Henik A, Carter CS, Salo R, Chaderjian M, Kraft L, Nordahl TE et al (2002). Attentional control and word inhibition in schizophrenia. Psychiatry Res 110: 137-149.

Hennings EC, Kiss JP, Vizi ES (1997). Nicotinic acetylcholine receptor antagonist effect of fluoxetine in rat hippocampal slices. Brain Res 759: 292-294.

Hershman KM, Freedman R, Bickford PC (1995). GABAB antagonists diminish the inhibitory gating of auditory response in the rat hippocampus. Neurosci Lett 190: 133-136.

Hughes J (1986). Prevalence of smoking among psychiatric outpatients. Am J Psychiatry 143: 993-997.

Jacobsen LK, D'Souza DC, Mencl WE, Pugh KR, Skudlarski P, Krystal JH (2004). Nicotine effects on brain function and functional connectivity in schizophrenia. Biol Psychiatry 55: 850-858.

Jentsch JD, Taylor JR (1999). Impulsivity resulting from frontostriatal dysfunction in drug abuse: implications for the control of behavior by reward-related stimuli. Psychopharmacology (Berl) 146: 373-390.

Kay SR (1991). Positive and Negative Syndromes in Schizophrenia. Brunner/Mazel: New York.

Kelton MC, Kahn HJ, Conrath CL, Newhouse PA (2000). The effects of nicotine on Parkinson's disease. Brain Cogn 43: 274-282.

Kumari V, Postma P (2005). Nicotine use in schizophrenia: the self medication hypotheses. Neurosci Biobehav Rev 29: 1021-1034.

Kumari V, Soni W, Sharma T (2001). Influence of cigarette smoking on prepulse inhibition of acoustic startle response in schizophrenia. Hum Psychopharmacol 16: 321-326.

Lawrence AD, Weeks RA, Brooks DJ, Andrews TC, Watkins LH, Harding $\mathrm{AE}$ et al (1998). The relationship between striatal dopamine receptor binding and cognitive performance in Huntington's disease. Brain 121(Pt 7): 1343-1355.

Le Houezec J, Halliday R, Benowitz NL, Callaway E, Naylor H, Herzig K (1994). A low dose of subcutaneous nicotine improves information processing in non-smokers. Psychopharmacology (Berl) 114: 628-634.

Leonard S, Adams C, Breese CR, Adler LE, Bickford P, Byerley W et al (1996). Nicotinic receptor function in schizophrenia. Schizophr Bull 22: 431-445.

Leonard S, Gault J, Hopkins J, Logel J, Vianzon R, Short M et al (2002). Association of promoter variants in the alpha7 nicotinic acetylcholine receptor subunit gene with an inhibitory deficit found in schizophrenia. Arch Gen Psychiatry 59: 1085-1096.

Levin ED, Conners CK, Silva D, Hinton SC, Meck WH, March J et al (1998). Transdermal nicotine effects on attention. Psychopharmacology (Berl) 140: 135-141.

Levin ED, Conners CK, Sparrow E, Hinton SC, Erhardt D, Meck WH et al (1996a). Nicotine effects on adults with attention- 
deficit/hyperactivity disorder. Psychopharmacology (Berl) 123: 55-63.

Levin ED, Wilson W, Rose JE, McEvoy J (1996b). Nicotinehaloperidol interactions and cognitive performance in schizophrenics. Neuropsychopharmacology 15: 429-436.

Mansvelder HD, van Aerde KI, Couey JJ, Brussaard AB (2006). Nicotinic modulation of neuronal networks: from receptors to cognition. Psychopharmacology (Berl) 184: 292-305.

Marder SR, Fenton W (2004). Measurement and Treatment Research to Improve Cognition in Schizophrenia: NIMH MATRICS initiative to support the development of agents for improving cognition in schizophrenia. Schizophr Res 72: 5-9.

Marder SR, Fenton W, Youens K (2004). Schizophrenia, IX: Cognition in schizophrenia-the MATRICS initiative. Am J Psychiatry 161: 25.

Martin LF, Kem WR, Freedman R (2004). Alpha-7 nicotinic receptor agonists: potential new candidates for the treatment of schizophrenia. Psychopharmacology (Berl) 174: 54-64.

McEvoy JP, Freudenreich O, Wilson WH (1999). Smoking and therapeutic response to clozapine in patients with schizophrenia. Biol Psychiatry 46: 125-129.

McGehee D, Heath M, Gelber S, Devay P, Role W (1995). Nicotine enhancement of fast excitatory synaptic transmission in the CNS by presynaptic receptors. Science 269: 1692-1696.

Mehta MA, Sahakian BJ, McKenna PJ, Robbins TW (1999). Systemic sulpiride in young adult volunteers simulates the profile of cognitive deficits in Parkinson's disease. Psychopharmacology (Berl) 146: 162-174.

Mumenthaler MS, Yesavage JA, Taylor JL, O'Hara R, Friedman L, Lee $\mathrm{H}$ et al (2003). Psychoactive drugs and pilot performance: a comparison of nicotine, donepezil, and alcohol effects. Neuropsychopharmacology 28: 1366-1373.

Myers CS, Robles O, Kakoyannis AN, Sherr JD, Avila MT, Blaxton TA et al (2004). Nicotine improves delayed recognition in schizophrenic patients. Psychopharmacology (Berl) 174: 334-340.

Newhouse PA, Potter A, Singh A (2004). Effects of nicotinic stimulation on cognitive performance. Curr Opin Pharmacol 4: 36-46.

Olincy A, Harris JG, Johnson LL, Pender V, Kongs S, Allensworth $\mathrm{D}$ et al (2006). Proof-of-concept trial of an alpha7 nicotinic agonist in schizophrenia. Arch Gen Psychiatry 63: 630-638.

Olincy A, Johnson LL, Ross RG (2003). Differential effects of cigarette smoking on performance of a smooth pursuit and a saccadic eye movement task in schizophrenia. Psychiatry Res 117: 223-236.

Olincy A, Ross R, Young D, Roath M, Freedman R (1998). Improvement in smooth pursuit eye movement after cigarette smoking in schizophrenic patients. Neuropsychopharmacology 18: $175-185$.

Picciotto MR, Caldarone BJ, King SL, Zachariou V (2000). Nicotinic receptors in the brain. Links between molecular biology and behavior. Neuropsychopharmacology 22: 451-465.

Postma P, Gray JA, Sharma T, Geyer M, Mehrotra R, Das M et al (2006). A behavioural and functional neuroimaging investigation into the effects of nicotine on sensorimotor gating in healthy subjects and persons with schizophrenia. Psychopharmacology (Berl) 184: 589-599.

Rezvani AH, Kholdebarin E, Dawson E, Levin ED (2007). Nicotine and clozapine effects on attentional performance impaired by the NMDA antagonist dizocilpine in female rats. Int $J$ Neuropsychopharmacol 1-8. Print copy in press (originally published online February 13, 2003 at http://journals.cambridge. org/action/displayJournal?jid = PNP).

Roberts RJ, Pennington BF (1996). An interactive framework for examining preforontal cognitive processes. Dev Neurosychol 12 105-126.

Sacco KA, Bannon KL, George TP (2004). Nicotinic receptor mechanisms and cognition in normal states and neuropsychiatric disorders. J Psychopharmacol 18: 457-474.

Sacco KA, Termine A, Seyal A, Dudas MM, Vessicchio JC, Krishnan-Sarin S et al (2005). Effects of cigarette smoking on spatial working memory and attentional deficits in schizophrenia: involvement of nicotinic receptor mechanisms. Arch Gen Psychiatry 62: 649-659.

Sherr JD, Myers C, Avila MT, Elliott A, Blaxton TA, Thaker GK (2002). The effects of nicotine on specific eye tracking measures in schizophrenia. Biol Psychiatry 52: 721-728.

Simpson PM, Surmon DJ, Wesnes KA, Wilcock GK (1991). The cognitive drug research computerized assessment system for demented patients: a validation study. Int J Geriatr Psychiatry 6: 95-102.

Slemmer JE, Martin BR, Damaj MI (2000). Bupropion is a nicotinic antagonist. J Pharmacol Exp Ther 295: 321-327.

Smith RC, Singh A, Infante M, Khandat A, Kloos A (2002). Effects of cigarette smoking and nicotine nasal spray on psychiatric symptoms and cognition in schizophrenia. Neuropsychopharmacology 27: 479-497.

Smith RC, Warner-Cohen J, Matute M, Butler E, Kelly E, Vaidhyanathaswamy S et al (2006). Effects of nicotine nasal spray on cognitive function in schizophrenia. Neuropsychopharmacology 31: 637-643.

Symonds CS, Gallagher P, Thompson JM, Young AH (2004). Effects of the menstrual cycle on mood, neurocognitive and neuroendocrine function in healthy premenopausal women. Psychol Med 34: 93-102.

Vink M, Ramsey NF, Raemaekers M, Kahn RS (2006). Striatal dysfunction in schizophrenia and unaffected relatives. Biol Psychiatry 60: 32-39.

Volkow ND, Fowler JS, Wang GJ, Swanson JM (2004). Dopamine in drug abuse and addiction: results from imaging studies and treatment implications. Mol Psychiatry 9: 557-569.

Volkow ND, Gur RC, Wang GJ, Fowler JS, Moberg PJ, Ding YS et al (1998). Association between decline in brain dopamine activity with age and cognitive and motor impairment in healthy individuals. Am J Psychiatry 155: 344-349.

Wechsler D (1997b). Wechsler Memory Scale-Third edition: Administration and Scoring Manual. Psychological Corporation: San Antonio, TX.

Weiss AP, Jubelt LE, Barr RS, Goff DC, Rigotti NA, Evins AE (2006). The Effect of Transdermal Nicotine on Episodic Memory Performance in Nonsmoking Patients with Schizophrenia. Neuropsychopharmacology 31: S112-113.

White HK, Levin ED (1999). Four-week nicotine skin patch treatment effects on cognitive performance in Alzheimer's disease. Psychopharmacology 143: 158-165.

Wonnacott S, Kaiser S, Mogg A, Soliakov L, Jones IW (2000). Presynaptic nicotinic receptors modulating dopamine release in the rat striatum. Eur J Pharmacol 393: 51-58.

Supplementary Information accompanies the paper on the Neuropsychopharmacology website (http://www.nature.com/ npp) 